\title{
Implementing mobile information technology in clinical nursing education: how, why, when, where and what happened? Some answers from a review of the literature
}

\author{
Siobhan O'Connor ${ }^{1 *}$, Tom Andrews ${ }^{2}$ \\ From Health Services Research: Evidence-based practice \\ London, UK. 1-3 July 2014
}

\section{Background}

Clinical practice presents a variety of challenges for nursing students which can impact their learning and application of knowledge and skills. Their inexperience coupled with the lack of supervision and ad hoc nature of learning in clinical environments can reduce their hands-on skills and negatively impact patient care. New methods are needed to help nursing students and educators address the theory-practice gap [1]. Information and communication technologies (ICT) such as mobile devices are being proposed as one way to support nursing students in clinical practice as they provide instant access to evidence based information at the point of care [2]. Despite the advantages it offers implementing mobile technology in clinical nursing education has proved challenging. The literature review aims to investigate how, why, when and where hand-held devices have been utilised in clinical nursing education and what factors facilitated or hindered their use.

\section{Materials and methods}

Online bibliographical databases including CINAHL, ERIC, MEDLINE, PubMed and The Cochrane Library were searched using a combination of key terms such as: mobile, handheld, personal digital assistant, PDA, smarpthone, tablet computer, technology, nurs", student, education, learning and training. Studies included in the review were primary research studies, published in English in peer reviewed journals between January 2000 and December 2013.

${ }^{1}$ Health Information Systems Research Centre, Department of Accounting, Finance and Information Systems, University College Cork, Cork, Ireland Full list of author information is available at the end of the article

\section{Results}

Of the 216 abstracts identified, 24 were included in the study. These articles highlight the homogeneity of mobile platforms currently in use, with personal digital assistants being the predominent device despite newer technologies being available. A variety of mobile applications and how they are used by nursing students in clinical practice is also summarised. Although a number of benefits to using mobile devices for clinical learning are identified these are limited by a multiplicity of socio-technical barriers.

\section{Conclusions}

Mobile technology has spawned a cultural shift creating continuous and pervasive access to data. These unique features can support nursing student to improve their knowledge, skills and clinical practice. However many barriers to implementing mobile devices still need to addressed before they become integrated into routine nursing practice.

\footnotetext{
Acknowledgements

This study was funded by the Health Research Board (HRB) and University College Cork's Presidents Award for Research into Innovative Forms of Teaching and Learning.

\section{Authors' details}

${ }^{1}$ Health Information Systems Research Centre, Department of Accounting, Finance and Information Systems, University College Cork, Cork, Ireland. ${ }^{2}$ Catherine McAuley School of Nursing and Midwifery, University College Cork, Cork, Ireland.
}

Published: 7 July 2014

\section{References}

1. Landers MG: The theory-practice gap in nursing: the role of the nurse teacher. Journal of Advanced Nursing 2000, 32:1550-1556. 
2. Bates DW, Gawande AA: Improving Safety with Information Technology. New England Journal of Medicine 2003, 348:2526-2534.

doi:10.1186/1472-6963-14-S2-P88

Cite this article as: $O^{\prime} C o n n o r$ and Andrews: Implementing mobile

information technology in clinical nursing education: how, why, when,

where and what happened? Some answers from a review of the literature.

BMC Health Services Research 2014 14(Suppl 2):P88.

Submit your next manuscript to BioMed Central and take full advantage of:

- Convenient online submission

- Thorough peer review

- No space constraints or color figure charges

- Immediate publication on acceptance

- Inclusion in PubMed, CAS, Scopus and Google Scholar

- Research which is freely available for redistribution

Submit your manuscript at 